Issue no. $24 / 2017$

\title{
CULTURAL DIVERSITY IN THE WORKPLACE - DISCOURSE AND PERSPECTIVES
}

\author{
Veronica Maria MATEESCU \\ Lecturer, $\mathrm{PhD}$ \\ Faculty of Sociology and Social Work, \\ Babeș-Bolyai University Cluj-Napoca \\ veronicamateescu@yahoo.com
}

DOI:10.24193/OJMNE.2017.24.02

\begin{abstract}
The main purpose of this article is to outline the various current theoretical positions in the discourse on cultural diversity at the organizational level and the practical implications deriving from these different types of discourses. The analysis identifies two major types of positioning: the managerial perspective and critical studies in diversity management. The practical consequences of certain theoretical stances are varied. Hence, in the first case, the emphasis is put on diversity management, on the advantages and disadvantages of cultural diversity in relation to organizational performance. In the second case, the emphasis is placed on power relations, social exclusion and the need to create inclusive professional climates.
\end{abstract}

Keywords: cultural diversity, workplace, managerial perspective, critical studies in diversity management

\section{General Considerations}

Cultural diversity in the workplace reflects the existent demographic, social and cultural differences on a societal level (Gotsis and Korte 2015). At level of the European Union, diversity management is considered to be an important pillar of the Europe 2020 strategy in creating a sustainable and inclusive economy (European Commission, 2012). This is due to the belief that through an effective diversity management, organizations gain numerous benefits, such as: an increase in creativity, an increase in staff retention and job satisfaction, an increase in consumer engagement, etc. (European Commission, 2012). Thus, 
Issue no. $24 / 2017$

since 2004, 13 national Diversity Charters have been implemented, with the EU-level Diversity Charter Platform being created in 2010, and a research conducted in 2014 showed that by joining this platform, the 13 charters were signed by more than 7,100 companies (enterprises, public bodies, NGOs), including over 13.6 million employees (European Commission, 2014). The diversity charter means: "(...) a short document voluntarily signed by companies which outlines the commitment of the undersigning organization to promote diversity and equal opportunities in the workplace, regardless of, for example, age, disability, gender, race or ethnic origin, religion or sexual orientation" (European Commission, 2014: $6)$.

At the organizational level, the concern for cultural diversity is central, mainly as a result of the global economy, which has brought the internationalization of organizations and a change in the composition of the workforce, primarily through immigration and guest workers. Also, global legislative trends concerning anti-discrimination oblige firms to adopt such policies with respect to their employees (Mor Barak, 2014). Thus, on an organizational level, a series of programs, practices and interventions are developed in order to capitalize on the positive aspects of a diverse workforce (Gotsis and Korte 2015). Most often, these are reflected in human resource practices, e.g.: increasing numerical representation of employees coming from minority/vulnerable groups (e.g.: criteria based on ethnicity, race, gender), mentoring, educational and diversity training programs (e.g. diversity and cultural awareness), work-life balance programs for vulnerable groups (e.g. women, people with certain religious affiliations, the elderly, etc.) (Gotsis and Korte 2015), new family friendly policies adapted to new types of family (Racolța-Paina and Andrieș, 2017). This concern for workplace cultural diversity is also reflected in the existing literature within this field of study, which has developed relatively recently into a scientific field (approximately 30 years ago). Thus, in the last 10 years there has been an increase of more than $110 \%$ in scholarly interest compared to the previous decade, and in the popular press there has been an increase of roughly $500 \%$ concerning the topic, as compared to the initial years of the field in the mid1980s (Jonsen, Maznevski and Schneider, 2011).

The preoccupation with cultural diversity in the workplace has its roots in the debate that began around the 1980s, concerning the influence of national culture on management and 
Issue no. $24 / 2017$

organizational practices and on the behavior of individuals. This debate was part of the broader discussion on the issue of cultural convergence - divergence in the field of management, the prevailing concept of that time being the existence of a "one best way"- type approach to manage organizations. It may be argued that the first theories that opened the way to studying the impact of culture on organizations are the theories of structural contingency, which questioned, even if only partially, the idea of a "one best way" kind of approach in organizational management and raised the issue of the existence of a relationship between organizations and their "environment", however, without explicitly focusing on culture as such. With the development of neoinstitutionalist theories, the issue of the influence of culture (this time explicitly included in the environment) and the relationship between the organization and society becomes clearer (Rojot, 2003). Thus, in the 1970s and 1980s, culture and its influence on the organization fell into the purview of organizational researchers, first in the form of the exchanges/relationships existing between a company and society (Bollinger and Hofstede, 1987). It is believed that the first author who formulated a theory that clearly demonstrated the existence of a relationship between culture and organization is Geert Hofstede (Segrestin, 1992), based on research that has shown that organizations are influenced by national culture (culture-bound), developing a model concerning the dimensions of national culture (Hofstede, 1996), and opening the way for popularizing some models that were not as well-known and for developing new ones. Although Hofstede's model, and generally the national culture model approach, is criticized (McSweeney, 2002), it continues to be a landmark within the literature and current research endeavors in the field.

This debate resulted in outlining a new field within organizational studies namely cross-cultural management. The central point of interest in cross-cultural management has been, and still is, the way in which national cultural differences influence the behavior of individuals within their work. Thus, cultural diversity was mainly understood as a national cultural difference. At the present time, this conception still persists; however, a critical trend has been emerging against it, the main argument of which being that of a deterministic, essentialist and positivist conception of national culture and the inadequacy of the concept of national culture. Cross-cultural management and diversity management are the two faces of 
Issue no. $24 / 2017$

the same coin, denoting the same reality, that of a diverse cultural workforce, cross-cultural management being used predominantly when there is a question of the existence of a diversity of national cultures.

Mor Barak (2014) notes a gradual change in diversity management theory and research, driven by increased cross-national collaboration that has led to new perspectives by highlighting the specificities of different contexts. Prior to this change, research into individual and intergroup differences in the workplace was poorly articulated, using different frameworks and terminology, resorting generally to social psychological theories on diversity, social identity and intergroup relations developed in North America and Western Europe. Currently, diversity management has become a distinct scientific research field and at an organizational level, specialized departments in Diversity and Inclusion (D \& I) have been created, which develop policies and practices in this respect (Mor Barak, 2014).

Nonetheless, engaging in a literature review of the field of diversity, Jonsen, Maznevski, Schneider (2011), concluded that the existing literature is not as diverse, being mainly dominated by US-centric research.

\section{Defining the Concept of Workplace Cultural Diversity}

A literature review of the fields of HR, organization, and business identifies several categories in which the definitions of cultural diversity can be included:

a) narrow category-based definitions - cultural diversity is defined by gender, racial, and ethnic differences. These definitions are determined by discrimination legislation, originating in the US and do not necessarily apply to other cultural and social contexts.

b) broad category-based definitions. Alongside the categories included in the narrow category-based definitions, there are a number of other variables, such as: age, education, marital status, cultural background, social class. Two subcategories can be distinguished within this category: visible diversity and invisible diversity. Visible diversity (e.g. race, gender, physical disability) represents a preferential basis for stereotypes, prejudices and biases more so than invisible diversity (religion, education, socio-economic status, etc.) Diversity also arises from the interaction between visible and invisible diversity, which often generates inferences about the person's internal attributes. 
c) definitions based on a conceptual rule (e.g. variety of perspectives, differences in the actions etc.) (Mor Barak, 2014).

Another approach in defining cultural diversity is based on the criteria/methods to differentiate individuals among themselves, making a distinction between primary, secondary and tertiary dimensions of diversity (Mazur, 2010). Primary dimensions include: gender, ethnicity, race, age, mental/physical abilities. Secondary dimensions refer to: religion, culture, sexual orientation, lifestyle, political orientation, work experience, education, language etc. And tertiary dimensions address: beliefs, assumptions, perceptions, attitudes, feelings, values. All these dimensions are seen as interacting in creating the identity of the individual, generating similarities and differentiations that affect the work environment. This perspective is a reaction to the conception that predominated in the organizational field, according to which diversity was only associated with multicultural, multiethnic and multiracial aspects (Mazur, 2010).

Mor Barak (2014) detects a problem in the discourse attempting to define cultural diversity, which lies in the enthusiasm and appreciation of diversity, often without presenting the way in which the existence itself of differences negatively impact individuals. Thus, he highlights focusing on benign differences (e.g. preferences concerning food, clothing, hair color), which are individual differences which lend unique qualities to human beings, while placing in the background those differences that practically and negatively impact individuals (race, ethnicity, sexual orientation, etc.), which are qualities given by a person's belonging to a certain group, with its positive or negative consequences. The results of Mor Barak's (2014) research on global corporations shows that diversity is defined by managers and employees, as a form of inclusion.

Analyzing the concept of workplace diversity, Gotsis and Kortezi (2015) point to the importance of understanding the existence of a contextual definition of cultural diversity, the criteria for forming individual and group identities varying in time, space and cultural contexts (e.g. gender). 
Issue no. $24 / 2017$

\section{Perspectives and Discourse on Cultural Diversity within Organizations}

\section{III.1. The Managerial Perspective and the Management of Cultural Diversity}

At an organizational level, the issue of cultural diversity management has been raised, as in formalized actions for its management, in the hopes of achieving a type of "harmony" that can be achieved through proper diversity management (Mor Barak 2014). The more or less explicitly articulated goal behind this demand is mainly increasing efficiency and individual and organizational performance. "Diversity management refers to a set of managerial actions aimed at either increasing diversity and/or promoting amicable, productive working relationships." (Jonsen, Maznevski and Schneider, 2011: 36).

Therefore, we can observe a managerial perspective on organizational cultural diversity, in which the latter is seen either as a resource or as an obstacle for performance and an element that can be used by the management in one way or another. This is the reason why management needs special skills to manage cultural diversity (Mazur, 2010).

The issue is addressed through the advantages and disadvantages of cultural diversity within an organization and its impact on organizational performance.

According to Milliken and Martins (apud Mazur, 2010), diversity influence the functioning of an organization by four types of mediating variables "affective consequences" (low satisfaction or organizational commitment), "cognitive outcomes" (increased creativity and innovation), "symbolic effects" (the reputation of an inclusive and egalitarian organization), "communication effects" (effective or poor communication).

Among the frequently mentioned advantages the following are included: enhancing innovation and creativity, increased efficiency in decision making and problem solving as a result of the many perspectives/experiences/backgrounds, high adaptability to change (Cox and Blake, 1991; Kearney et al., 2009; Mazur, 2010), reducing the group thinking effect (Barinaga, 2007). The less-favored advantages, mainly mentioned by sociologists, are the promotion of inclusion and acceptance in the workplace (Gossen, 2016).

Starting from the conception of cultural diversity in terms of national cultural differences, often times the performance of nationally homogeneous groups and that of nationally heterogeneous groups are compared. In a study focused on group work on international projects, Barinaga (2007), Chevrier (2000) show how national culture and 
Issue no. $24 / 2017$

cultural diversity are instrumentalized in order to justify the differences in performance. Such an approach gives cultural differences a positivist status, a single explanatory variable, falling within a deterministic perspective (Barinaga, 2007). Barinaga (2007), Ailon-Souday \& Kunda (2003) complete the image according to which national culture and cultural diversity are used by members of the group as a discursive resource in their everyday interaction, to explain/justify confusion, misunderstanding, to position and justify actions/decisions towards the group. According to this perspective, national culture is not something predetermined, cultural diversity is not an objective reality, but a discourse produced and reproduced continuously by individual actors in their daily interactions. (...) "group members use "national culture" and "cultural diversity" as tools to get organized, reproducing the truth effects of "cultural differences" (Barinaga, 2007: 3).

The opposing position states that cultural diversity negatively influences the performance of the group. The negative results of cultural diversity on the group's performance are explained through theories of social identity and self-categorization (Barinaga, 2007; Mazur, 2010). According to these theories, the heterogeneity of the group decreases the level of communication within the group, as well as the level of satisfaction and cooperation, while increasing emotional conflicts, as the social comparison and categorization processes as well as in-groups/out-groups and cognitive biases are more present than in the case of homogeneous groups (Mazur, 2010). Several research findings show that these are more common in medium-heterogeneity groups than in very diverse ones, in which there is a high level of heterogeneity, where conflicts and identifying with the group disperse as a result of frequent interactions with members from the out-groups (Mazur, 2010).

Other perceived disadvantages of cultural diversity are: the consumption of energy, time and resources for problem solving, confusion and frustration resulting from a high degree of uncertainty and complexity, difficulty in obtaining an agreement in the decision making process, low level of identification with the group and organizational integration leading to low performance (Mazur, 2010). Add to this increasingly hostile social environments towards those who look/behave differently from the mainstream, as a result of the reinforcement of national identity - "In the public and political spheres, there is 
Issue no. $24 / 2017$

increasing talk about erecting walls, both physically and metaphorically" (Mor Barak, 2014: xvi).

Barinaga (2007), however, considers the results of research into the advantages or disadvantages of the organization in terms of organizational performance to be inconclusive. His explanation is that mixed and contradictory results derive from the positivist conception of national culture, seen as the only explanatory variable of different behaviors that lead or not to performance.

This conception is derived from the wider, predominant conception of cross-cultural management, according to which there are a series of dimensions of national culture that influence the behavior of individuals in that particular culture (Kluckhohn and Strotdbeck, Hofstede, Trompenaars, etc.), national culture being seen as a form of collective mental programming (Barinaga, 2007). This effect is accentuated when working with an antiquated, semi-digested and simplified bibliography produced before 1970 in the field of cultural anthropology. Typically in these cases, culture is approached from an essentialist, structuralist (Staber, 2006) and positivist (Aycan, 2000) perspective, the main consequence being the neglect of cultural interactions that take place within an organization. Moreover, these models have a limited capacity to explain and predict organizational behavior at a micro level (Yeganeh, Su, 2006) and do not take into account other factors such as organizational, economic, individual, contextual, and other factors. Since the essentialist perspective conceives culture as having clearly defined boundaries, individuals are defined by their affiliation with a particular culture, from which they cannot escape; this affiliation differentiates them from other individuals, who are, in turn, carriers of another culture (Grillo, 2003). Culture as a structure is seen as a normative and interpretive framework for individual experiences with a high degree of stability, which would imply a high degree of stability also with regards to the orientations and motivations of individuals (Staber, 2006). The positivist approach of culture is based on the premise that it is an objective phenomenon, which can be measured, observed and analyzed with precision (Yeganeh, Su, 2006). 
Issue no. $24 / 2017$

\section{2. Critical Studies in Diversity Management}

Positivist managerial discourse on workplace cultural diversity continues, being still a prevalent part of the existing literature within the field, although about 20 years ago a critical reaction against it emerged (Gotsis and Korte 2015), with new sub-disciplines arising within the literature (e.g. context-sensitive studies of diversity policies/management in practice Dobusch, 2017; Tomlinson and Schwabenland, 2010 Zanoni and Janssens, 2007; critical studies in diversity management - Gotsis and Korte 2015).

Dobusch (2017) summarizes the main criticisms on cultural diversity brought on by the managerial perspective:

a) the existence of an insurmountable distance between economic/business reasons and social justice reasoning;

b) the lack of consensus on producing a considerable impact through "diversity turn" on the growth of historically disadvantaged groups and that of inclusion in general;

c) the existence of doubts/reservations concerning the effectiveness of policies/diversity management

d) creating a superficial image of diversity, without changing organizational practices, structures and culture;

e) focusing on practices that target the individual (e.g.: diversity training) and failing to take into account the power relationships at an organizational level that generate organizational inclusion/exclusion policies;

f) an essentialist and homogenizing perspective on diversity - a distinction between groups on the basis of one-dimensional, fixed criteria (e.g. gender or race, etc.) and not taking into account individual diversity within the group;

g) the inclusion of historically vulnerable groups into the diversity category, which in fact strengthens the distinction between them and other groups (e.g. those at the managerial level who are in charge of managing cultural diversity).

In their synthesis of the literature on critical studies in diversity management Gotsis and Kortezi (2015) highlight the main theoretical premises and its contributions to the field:

a. a non-essentialist, non-positivistic concept of diversity; 
Issue no. $24 / 2017$

b. the influence of a social context on the way in which the different sociodemographic identities that are the sources of diversity at the organizational level are defined and constructed;

c. highlighting power relations, inequalities and the role of different social actors in a particular social context that generate certain meanings of diversity;

To this we can add that the managerial perspective does not take into account the real political stakes at the organizational level of the existence of cultural diversity, with various work environments having the potential of becoming hostile and discriminatory environments where social exclusion is practiced on the basis of different criteria (e.g. nationality, ethnicity, language, religion, race, gender, social class, etc.). Social exclusion through open practices resulting from either the formal or informal policies of the organization is one of the main problems facing the workforce in national and international work environments, an issue highlighted by several authors (Mor Barak, 2014).

Among exclusion practices the following are included: exclusion from professional opportunities, informational networks, participating in teams, investment in human resources, positions of power, engagement in decision-making as a result of an affiliation or perceived affiliation by the employer to a minority or disadvantaged group, based on negative stereotypes (Mor Barak, 2014). For the individuals affected, exclusion generates the feeling that they are not seen as an integral part of the organization, being used as a justification for their dissatisfaction concerning their role in the organization and their decision to leave a job (Mor Barak, 2014). Because inclusion is positively correlated with career advancement, job satisfaction, professional opportunities, well-being, work performance, organizational commitment, all of these aspects have a direct influence on the decision to stay in or to leave a job (Mor Barak, 2014).

Mor Barak (2014) proposes to overcome the managing diversity stage by creating an inclusive climate. According to his own definition (Nishii, 2013: 1754), an inclusive climate is one "(...) which involves eliminating relational sources of bias by ensuring that identity group status is unrelated to access to resources, creating expectations and opportunities for heterogeneous individuals to establish personalized cross-cutting ties, and integrating ideas across boundaries in joint problem solving." 
Issue no. $24 / 2017$

\section{Conclusion}

Cultural diversity is a reality of organizational life, one that has generated concerns about its management, the social exclusion produced, and the creation of an inclusive environment. However, beyond the different theoretical positions and the practical implications of the concept, I believe there are a number of aspects that are not taken into account. For example, the discourse on cultural diversity practiced at large corporations does not take into account the practices of labor exploitation, abuses, poorly paid work in different countries, usually the poorly developed one, where they have subsidiaries that operate as subcontractors, etc., where the cost advantage prevails. Generally, in these cases, when the matter of exploitation and abuse are brought to the forefront, the generic issue of human rights violations is cited. Nonetheless, it concerns a "generic" human being, if we could use that term, as in without highlighting their socio-demographic characteristics, economic conditioning, social positioning, occupation, professional qualification, position within the organization, etc. Thus, it raises a number of questions that may represent new research endeavors: What are the legal, political, socio-cultural contexts in which the issues of diversity, diversity management, social exclusion, the need for an inclusive climate are raised? When the interest dictates that the main priority of a business is cost advantage, can one still speak of the matter of respecting diversity and inclusion?

Additionally, there is a need for a more in-depth study of diversity and diversity management at the level of SMEs where there is often a lack of the knowledge, skills, and structures needed to address the issue. This can lead to the enrichment of the field's theoretical and practical approaches, by having access to a reality that is less biased by the social desirability of the discourse concerning cultural diversity.

\section{Bibliography}

1. AYCAN, Z. (January 2000). Cross-cultural Industrial and Organizational Psychology. Contributions, Past Developments, and Future Directions. Journal of Cross-Cultural Psychology, 31 (1): 110-128. 
2. BARINAGA, E. (2007). "'Cultural diversity' at work: 'National Culture' as a discourse organizing an international project group". Human Relations, 60(2): 315-340.

3. BOLlingER, D., HOFSTEDE, G. (1987). Les différences culturelles dans le management. Comment chaque pays gère-t-il ses hommes?, Les Éditions d'Organisations, Paris.

4. CHEVRIER, S. (2000), Le management des équipes interculturelles, Presses Universitaires de France, Paris.

5. COX, T.H., BLAKE, S. ((Aug., 1991). Managing Cultural Diversity: Implications for Organizational Competitiveness. The Executive, 5 (3): 45-56.

6. DOBUSCH, L. (2017). Diversity discourses and the articulation of discrimination: the case of public organisations. Journal of Ethnic and Migrations Studies, 43:10, 1644-1661.

7. EUROPEAN COMISSION (2014). Overview of Diversity Management implementation and impact amongst Diversity Charter signatories in the European Union, http://ec.europa.eu/justice/discrimination/files/diversity_report2014_en.pdf, [accessed on $11 / 11 / 2017]$.

8. EUROPEAN COMISSION (2012). Realising the business benefits with European Diversity Charters. Managing Diversity at Work, http://ec.europa.eu/justice/discrimination/files/managing_diversity_atwork_en.pdf, [accessed on 18/11/2017].

9. GOTSIS G., Kortezi Z. (2015). Critical Studies in Diversity Management Literature, SpringerBriefs in Psychology, Springer Science+Business Media Dordrecht.

10. GRILLO, R.-D. (2003). Cultural Essentialism and Cultural Anxiety. Anthropological Theory. 3(2): 157-173.

11. HOFSTEDE, G. (1996). Managementul structurilor multiculturale. Software-ul gândirii, Ed. Economică, Bucureşti.

12. JONSEN, K., MAZENVSKI, M., SCHNEIDER, S.-C. (2011). Diversity and it's not so diverse literature: An international perspective. International Journal of Cross-Cultural Management, II(I): 35-62. 
13. KEARNEY, E., GEBERT, D., VOELPEL, S.-C. (2009). When and how diversity benefits teams: the importance of team members' need for cognition. Academy of Management Journal, 52(3): 581-598.

14. MAZUR, B. (November 2010). Cultural Diversity in Organisational Theory and Practice. Journal of Intercultural Management, 2(2): 5-15.

15. McSWEENEY, B. (January 2002). Hofstede's Model of National Cultural Differences and Their Consequences: a Triumph of Faith - a Failure of Analysis. Human Relations, 55(1): 89-118.

16. MOR BARAK, M.-E. (2014). Managing Diversity: Toward a Globally Inclusive Workplace, 3rd Edition, Sage, Los Angeles.

17. NISHII, L.-H. (2013). The Benefits of Climate for Inclusion for Gender-Diverse Groups. Academy of Management Journal, 56(6): 1754-1774.

18. RACOLT,A-PAINA, N.-D., ANDRIEȘ, A.-M. (2017). "New Perspectives on Family Friendly Policies from the Stakeholders' Point of View". On-line Journal Modelling the New Europe, 22: 57-84

19. ROJOT, J. (2003). Théorie des organisations, Paris, Éditions Eska.

20. SEGRESTIN, D. (1992). Sociologie de l'entreprise, Armand Collin, Paris.

21. STABER, U. (2006). Social Capital Processes in Cross Cultural Management. International Journal of Cross Cultural Management, 6(2): 189-203.

22. YEGANEH, H., Su, Z. (2006). Conceptual Foundations of Cultural Management Research. International Journal of Cross-Cultural Management. 6(3): 361-376. 